Alimentary Tract

\title{
Patients' real-world experience with inflammatory bowel disease: A cross-sectional survey in tertiary care centres from the GETAID group
}

\author{
Maria Nachury ${ }^{\mathrm{a}}$, Yoram Bouhnik ${ }^{\mathrm{b}}$, Melanie Serrero ${ }^{\mathrm{c}}$, Jerome Filippi ${ }^{\mathrm{d}}$, Xavier Roblin ${ }^{\mathrm{e}}$, \\ Julien Kirchgesner ${ }^{\mathrm{f}}$, Guillaume Bouguen ${ }^{\mathrm{g}}$, Denis Franchimont ${ }^{\mathrm{h}}$, Guillaume Savoye ${ }^{\mathrm{i}}$, \\ Anthony Buisson ${ }^{\mathrm{j}}$, Edouard Louis ${ }^{\mathrm{k}}$, Stephane Nancey ${ }^{\mathrm{l}}$, Vered Abitbol ${ }^{\mathrm{m}}$, \\ Jean-Marie Reimund ${ }^{\mathrm{n}}$, Olivier DeWit $^{\mathrm{O}}$, Lucine Vuitton ${ }^{\mathrm{p}}$, Nicolas Matthieu ${ }^{\mathrm{q}}$, \\ Laurent Peyrin-Biroulet ${ }^{\mathrm{r}}$, Cyrielle Gilletta ${ }^{\mathrm{s}}$, Sara Tadbirit, Matthieu Allez ${ }^{\mathrm{u}}$, \\ Stephanie Viennot ${ }^{\mathrm{v}}$, Arnaud Bourreille ${ }^{\mathrm{w}}$, David Laharie ${ }^{\mathrm{x}}$, Aurelien Amiot ${ }^{\mathrm{t}, *}$, on behalf of \\ the GETAID-patient experience study group ${ }^{1}$
}

a Department of Gastroenterology, CHU Lille, Service des Maladies de l'appareil digestif, F-59000 Lille, France

${ }^{b}$ Department of Gastroenterology, IBD and Nutrition Support, Beaujon Hospital, University Paris 7 Denis Diderot, Clichy, France

${ }^{\mathrm{c}}$ Hôpital Nord, Centre d'investigation clinique Marseille Nord, Université Méditerranée, Marseille, France

${ }^{\mathrm{d}}$ Department of Gastroenterology and Clinical Nutrition, CHU of Nice, University Côte d'Azur, Nice, France

e Department of Gastroenterology, Saint-Etienne University Hospital, Saint-Etienne, France

${ }^{\mathrm{f}}$ Department of Gastroenterology, AP-HP, Hôpital Saint-Antoine, F-75012, ERL 1057 INSERM/UMRS 7203, UPMC Université Paris 6, Paris, France

${ }^{g}$ Department of Gastroenterology, CHU Rennes and University of Rennes, INCERM, CIC1414, NUMECAN institute, F-35000 Rennes, France

${ }^{\mathrm{h}}$ Department of Gastroenterology, Hôpital Erasme, Laboratoire de Gastroenterologie experimentale, ULB, Brussels, Belgium

i Department of Gastroenterology, Rouen University Hospital, Rouen, France

j Department of Hepato-Gastroenterology, University Hospital Estaing of Clermont-Ferrand, Université d'Auvergne, Clermont-Ferrand, France

${ }^{\mathrm{k}}$ Department of Gastroenterology, Liège University Hospital, CHU Liège, Belgium

${ }^{1}$ Department of Gastroenterology, Lyon-Sud hospital, Hospices Civils de Lyon and INSERM U1111, University Claude Bernard Lyon 1, Lyon, France

m Department of Gastroenterology, Cochin University Hospital, Paris, France

${ }^{n}$ Service d'Hépato-Gastroentérologie et d'Assistance Nutritive, Hôpitaux Universitaires de Strasbourg (Hôpital de Hautepierre) et INSERM U1113 IRFAC

(Interface de Recherche Fondamentale et Appliquée en Cancérologie), Université de Strasbourg, Strasbourg, France

${ }^{\circ}$ Cliniques Universitaires Saint-Luc, UCL, Brussels, Belgium

p Department of Gastroenterology, Besancon University Hospital, Besancon, France

${ }^{q}$ Department of Hepato-Gastroenterology and Digestive Oncology, Grenoble Alpes University Hospital, Grenoble, France

${ }^{\mathrm{r}}$ Department of Gastroenterology, Nancy Universisty Hospital, Inserm U1256 NGERE, Lorraine University, Vandoeuvre-les-Nancy, France

${ }^{s}$ Department of Gastroenterology, Toulouse University Hospital, Toulouse, France

${ }^{\mathrm{t}}$ Department of Gastroenterology, Henri Mondor Hospital, APHP, EC2M3-EA7375, Paris Est-Créteil Val de Marne University, Creteil, France

u Department of Gastroenterology, Saint-Louis University Hospital, Paris, France

${ }^{v}$ Department of Gastroenterology, Caen University Hospital, Caen, France

w Department of Gastroenterology, Nantes University Hospital, Nantes, France

${ }^{x}$ Department of HepatoGastroenterology and Digestive Oncology, CHU Bordeaux, INSERM CIC 1401, Centre Medico-chirurgical Magellan, Haut-Leveque

Hospital, Université de Bordeaux; Bordeaux, France

\section{A R T I C L E I N F O}

\section{Article history:}

Received 17 July 2020

Accepted 12 October 2020

Available online $\mathrm{xxx}$

\section{Keywords:}

Crohn's disease

Inflammatory bowel disease

Patients experience

Ulcerative colitis

\section{A B S T R A C T}

Background: Patients' experience with healthcare professionals could influence their clinical outcomes. Aims: To assess inflammatory bowel disease (IBD) patients' experience with their disease, their treatment and their relationship with their physician.

Methods: A one-week cross-sectional study was conducted in 42 IBD centres. 2011 consecutive outpatients with IBD completed an anonymous self-report questionnaire assessing their experience with and knowledge of IBD.

\footnotetext{
All of the members of the GETAID patient experience study group are listed in the appendix.

* Corresponding author.

E-mail address: aurelien.amiot@hmn.aphp.fr (A. Amiot).

1 Members of the GETAID-patient experience study group are listed in the Appendix (following the References).
} 
Results: A quantitative assessment of the doctor-patient relationship revealed that patients' knowledge of IBD and IBD treatment ranged from 7.4 to 8.3 out of 10. In addition to IBD physicians, other sources of information about IBD and current treatment mainly included the internet ( $80 \%$ and $63 \%$, respectively) and general practitioners (61\% and 54\%). Knowledge about education programmes (28\%) was poor, resulting in a lack of willingness to further use these resources (25\%). Concerns about IBD treatment were raised in $76 \%$ of patients, mostly related to the fear of adverse events (47\%) and a lack of efficacy (33\%). The need of alternative healthcare professionals was reported by $89 \%$ of the sample.

Conclusion: In a large cohort of patients, we highlighted gaps in the management of patients with IBD regarding the need for higher-quality information and the implementation of alternative healthcare professionals.

(c) 2020 Editrice Gastroenterologica Italiana S.r.l. Published by Elsevier Ltd. All rights reserved.

\section{Introduction}

The advent of biological agents has dramatically changed the management of patients with inflammatory bowel disease (IBD) $[1,2]$. Beyond the standardization of more ambitious clinical outcomes, the consideration of the impact of IBD on patients' quality of life is now a standard of care [3]. Patients' experiences with IBD are multidimensional, including disability and doctor-patient relationships, and these experiences could influence clinical outcomes and treatment adherence [4]. Such perspectives have often been driven by physicians through Delphi and consensus processes based on their own experience. However, few studies have recently assessed patients' experiences with IBD.

The management of patients with IBD requires patientprofessional interactions between patients and multidisciplinary care teams, which include physicians and nurses and other healthcare providers such as psychologists, social workers or physiotherapists [5,6]. There is little information regarding IBD patients' experience with healthcare providers and their perceived needs in IBD.

We recently identified 3124 hospital visits of IBD patients in 42 IBD centres during a one-week cross-sectional survey [7]. Therefore, we conducted a large real-world cross-sectional survey of adult patients with IBD in 42 centres of the Groupe d'Etude Thérapeutique des Affections Inflammatoires du tube Digestif (GETAID) group to describe patients' experience with IBD in order to identify gaps and opportunities for improvement.

\section{Patients ad methods}

\subsection{Study population}

A one-week cross-sectional survey was conducted in 42 tertiary centres affiliated with the GETAID group in France and Belgium. The survey was conducted from November 26th to November 30th, 2018. Investigators were asked to include consecutive ambulatory adult ( $>18$ years) outpatients with a proven diagnosis of IBD. The paper questionnaire was distributed to patients by their GI specialist or IBD nurse, retrieved before the visit and entered into an anonymous electronic database.

The study was conducted in accordance with the ethical principles expressed in the Declaration of Helsinki and the requirements of applicable French regulations. The patients' experience study was conducted through the French reference methodology MR-004, supervised by and registered in the GETAID (registration number 2210131). All authors had access to the study data and reviewed and approved the final manuscript.

\subsection{Survey instrument}

A 4-page self-report questionnaire was first designed by the Educational GETAID Committee and then submitted to twenty con- secutive outpatients to assess completion rate and reliability of the questionnaire. The final questionnaire, which is provided in the supplementary materials (Fig. S1), was designed to explore the following:

- Patients and IBD characteristics: demographics, type and duration of IBD, age at diagnosis, history of surgical treatment, current medical IBD treatment, occupational status, distance between home and the IBD clinic.

- IBD activity: Overall health and IBD daily-life burden, measured using a 10-point Visual Analogue Scale (VAS), history of sickleave and patient's global assessment of clinical remission.

- Patients' overall satisfaction with the patient-physician relationship, measured using a 10-point VAS, as well as the frequency of appointments with physicians and general practitioners.

- Knowledge about IBD and IBD-related treatment, measured using a 10-point VAS as well as questions about the source of information and knowledge about biosimilars and educational programmes.

- Use of complementary and alternative medicine, measured using a 10 -point VAS.

- Adherence to IBD-related treatment, measured using a 10-point VAS.

- Concerns about IBD-related treatment, measured using a multiple choice question.

- Current use of and perceived need for healthcare providers, measured using multiple choice questions.

\subsection{Statistical analysis}

The data are expressed as numbers (\%) for qualitative data and as the means \pm standard deviation (SD) or medians [interquartile range] for quantitative data. Qualitative variables were compared using $\mathrm{Chi}^{2}$ test or the Fisher exact test and quantitative variables using Mann-Whitney test. All of the analyses were two-tailed, and $\mathrm{p}$ values less than 0.05 were considered significant. All statistics were calculated using the SPSS Statistics ${ }^{\circledR}$ software (SPSS Inc., v23, Chicago, IL, USA).

\section{Results}

\subsection{Study population}

We included 2011 outpatients with IBD, including 67.8\% with Crohn's disease (CD) and 32.2\% with ulcerative colitis (UC.). The main characteristics of the study population are shown in Table 1. The median duration of IBD was 10.5 [4.5-18.5] years. At the time of the survey, most of the patients $(73.9 \%)$ were treated with a biological agent, $8.5 \%$ were treated with an immunosuppressant alone, $11.6 \%$ were treated with 5 -aminosalicylic acid, and $6.3 \%$ had no treatment. A total of $70.6 \%$ of patients were employed or students, $8.5 \%$ were unemployed, $8.5 \%$ were homemakers, and $12.3 \%$ were retired. The mean distance between home and the IBD clinic 
Table 1

Demographic and disease and medication characteristics of 2011 patients with inflammatory bowel disease.

\begin{tabular}{|c|c|c|}
\hline Characteristic & Overallpopulation $(n=2011)$ & Missing data(\%) \\
\hline Age at diagnosis, years & $40.0[29.0-52.0]$ & $1.8 \%$ \\
\hline Male gender, no (\%) & $53.1 \%$ & $2.4 \%$ \\
\hline BMI, $\mathbf{k g} / \mathrm{m}^{2}$ & $24.4 \pm 6.5$ & $2.9 \%$ \\
\hline Duration of IBD, years & $10.5[4.5-18.5]$ & $10.2 \%$ \\
\hline Age at diagnosis, no (\%) & & $10.2 \%$ \\
\hline $\mathrm{A} 1: \leq 16$ years & $14.2 \%$ & \\
\hline A2: $17-40$ years & $67.6 \%$ & \\
\hline A3: $>40$ years & $18.2 \%$ & \\
\hline Type of inflammatory bowel disease, (\%) & & $5.1 \%$ \\
\hline Crohn's disease & $67.8 \%$ & \\
\hline Ulcerative colitis & $32.2 \%$ & \\
\hline History of intestinal resection, no (\%) & $45.6 \%$ & $2.4 \%$ \\
\hline Occupational status, $\%$ & & $3.8 \%$ \\
\hline Employed & $62.2 \%$ & \\
\hline Unemployed & $8.6 \%$ & \\
\hline Homemaker & $8.5 \%$ & \\
\hline Student & $8.4 \%$ & \\
\hline Retired & $12.3 \%$ & \\
\hline Distance from home, $\mathrm{km}$ & $46.8 \pm 99.6$ & $12.0 \%$ \\
\hline Current treatment & & $4.9 \%$ \\
\hline None & $6.3 \%$ & \\
\hline 5 -ASA & $11.6 \%$ & \\
\hline Immunosuppressant alone & $8.5 \%$ & \\
\hline Anti-TNF & $56.0 \%$ (including $14.9 \%$ with combination therapy) & \\
\hline Vedolizumab & $11.1 \%$ (including $1.0 \%$ with combination therapy) & \\
\hline Ustekinumab & $6.8 \%$ (including $0.9 \%$ with combination therapy) & \\
\hline Clinical remission & $49.1 \%$ & $14.3 \%$ \\
\hline
\end{tabular}

5-ASA: 5-aminosalicylic acid; TNF: tumor-necrosis factor; BMI: body mass index; GI: gastrointestinal; IBD: inflammatory bowel disease.

Variables are presented as $\mathrm{n}(\%)$, mean \pm standard deviation or median (interquartile range).

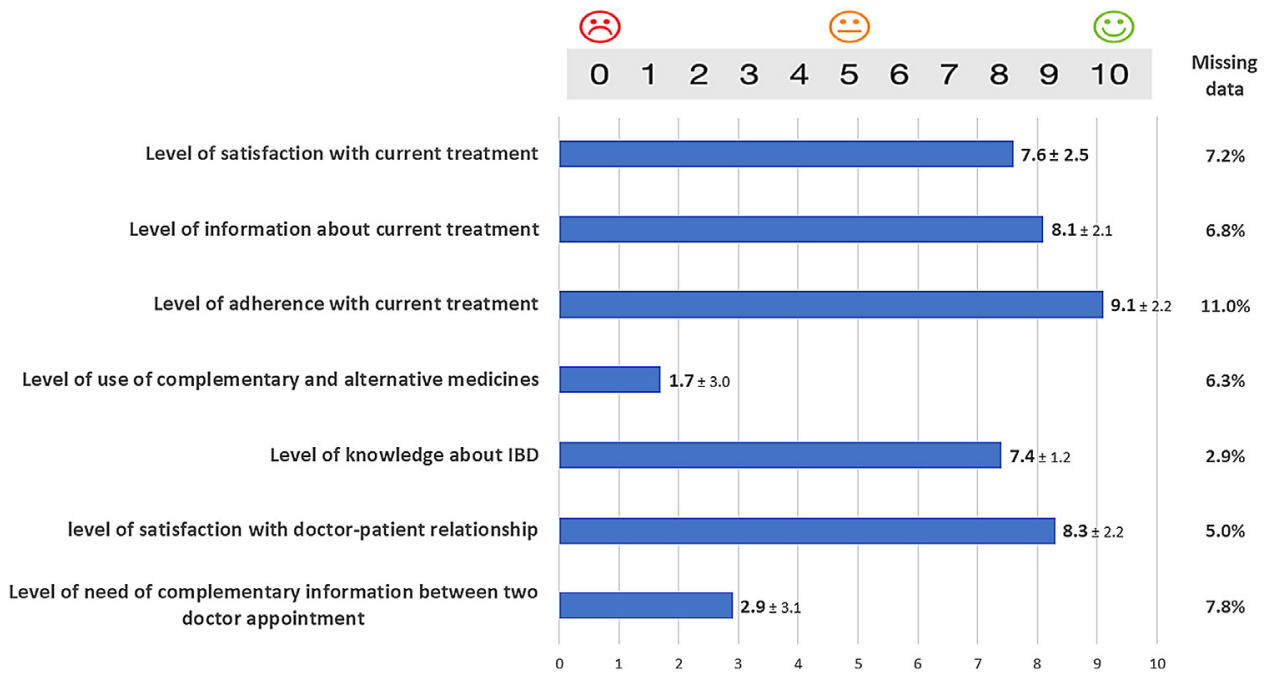

Fig. 1. Visual analogic scales to evaluate patients' experiences in IBD.

was $46.8 \pm 99.6 \mathrm{~km}$. Clinical remission was reported in $49.1 \%$ of patients.

\subsection{Patients experience with IBD}

Patients' perceived knowledge of IBD had a mean score of $7.4 \pm$ 1.2 (Fig. 1). Patients' perceived knowledge of IBD was higher in patients with long duration of IBD ( $>10$ years), history of intestinal resection, early diagnosis of IBD according to Montreal classification and patients in clinical remission. In addition to treating physicians, the main complementary sources of information on IBD were the internet (79.8\%), general practitioners (61.4\%), newspapers and magazines (29.0\%), patients associations (20.6\%), pharmacists (10.9\%) and educational programmes (8.0\%). A total of $97.4 \%$ of patients reported having free dialogue about their IBD with family members, $80.5 \%$ reported having free dialogue with their friends, $48.9 \%$ reported having free dialogue with their coworkers, and 39.3\% reported having free dialogue with other IBD patients. Regarding dedicated education programmes on IBD, $28.2 \%$ had knowledge of educational programmes patients, $10.4 \%$ had already participated, and $25.1 \%$ were willing to participate. Regarding sick leave, $71.2 \%$ of patients reported taking sick leave at least once since their IBD diagnosis, and the mean frequency of sick leaves per year was $0.8 \pm 1.8$.

\subsection{Patients experience with current treatment}

The levels of satisfaction with and information about current treatment were very good, with mean scores of $7.6 \pm 2.5$ and $8.1 \pm$ 2.1, respectively (Fig. 1). The level of information was higher in 
Table 2

Digestive and Liver Disease $x x x(x x x) x x x$

Visual analogic scales to evaluate patients' experiences in IBD according to patients' characteristics.

\begin{tabular}{|c|c|c|c|c|c|c|c|c|c|c|c|c|}
\hline & \multicolumn{2}{|c|}{$\begin{array}{l}\text { Level of knowledge } \\
\text { about IBD }\end{array}$} & \multicolumn{2}{|c|}{$\begin{array}{l}\text { Level of satisfaction } \\
\text { with current } \\
\text { treatment }\end{array}$} & \multicolumn{2}{|c|}{$\begin{array}{l}\text { Level of information } \\
\text { about current } \\
\text { treatment }\end{array}$} & \multicolumn{2}{|c|}{$\begin{array}{l}\text { Level of adherence to } \\
\text { current treatment }\end{array}$} & \multicolumn{2}{|c|}{$\begin{array}{l}\text { Level of satisfaction } \\
\text { with doctor-patient } \\
\text { relationship }\end{array}$} & \multicolumn{2}{|c|}{$\begin{array}{l}\text { Level of need of } \\
\text { complementary } \\
\text { information between } \\
\text { two doctor } \\
\text { appointment }\end{array}$} \\
\hline & VAS & $\mathrm{p}$ & VAS & $\mathrm{p}$ & VAS & $\mathrm{p}$ & VAS & $\mathrm{p}$ & VAS & $\mathrm{p}$ & VAS & $\mathrm{p}$ \\
\hline Gender & & 0.61 & & 0.20 & & 0.19 & & 0.45 & & 0.39 & & 0.01 \\
\hline Male & $7.4 \pm 1.8$ & & $7.7 \pm 2.5$ & & $8.1 \pm 2.1$ & & $9.0 \pm 2.3$ & & $8.3 \pm 2.2$ & & $2.7 \pm 3.2$ & \\
\hline Female & $7.5 \pm 1.9$ & & $7.5 \pm 2.4$ & & $9.0 \pm 2.1$ & & $9.1 \pm 2.1$ & & $8.4 \pm 2.2$ & & $3.1 \pm 3.1$ & \\
\hline Age & & 0.53 & & 0.47 & & 0.11 & & 0.003 & & 0.001 & & 0.30 \\
\hline$<40$ years & $7.4 \pm 1.8$ & & $7.6 \pm 2.4$ & & $8.0 \pm 2.1$ & & $8.9 \pm 2.3$ & & $8.1 \pm 2.2$ & & $2.9 \pm 3.0$ & \\
\hline $40-60$ years & $7.4 \pm 1.9$ & & $7.5 \pm 2.5$ & & $8.0 \pm 2.1$ & & $9.1 \pm 2.2$ & & $8.4 \pm 2.2$ & & $3.0 \pm 3.2$ & \\
\hline$>60$ years & $7.6 \pm 2.0$ & & $7.7 \pm 2.6$ & & $8.3 \pm 2.1$ & & $9.5 \pm 1.8$ & & $8.7 \pm 2.0$ & & $2.7 \pm 3.3$ & \\
\hline Type of IBD & & 0.12 & & 0.56 & & 0.70 & & 0.02 & & 0.01 & & 0.01 \\
\hline Crohn's disease & $7.5 \pm 1.8$ & & $7.6 \pm 2.4$ & & $8.1 \pm 2.1$ & & $9.0 \pm 2.3$ & & $8.2 \pm 2.2$ & & $2.8 \pm 3.0$ & \\
\hline Ulcerative colitis & $7.4 \pm 1.8$ & & $7.6 \pm 2.5$ & & $8.0 \pm 2.1$ & & $9.2 \pm 1.9$ & & $8.5 \pm 2.1$ & & $3.2 \pm 3.2$ & \\
\hline Past intestinal resection & & 0.01 & & 0.69 & & 0.86 & & 0.91 & & 0.19 & & 0.78 \\
\hline Yes & $7.6 \pm 1.8$ & & $7.6 \pm 2.5$ & & $8.1 \pm 2.1$ & & $9.1 \pm 2.3$ & & $8.4 \pm 2.1$ & & $2.9 \pm 3.1$ & \\
\hline No & $7.3 \pm 1.8$ & & $7.6 \pm 2.4$ & & $8.0 \pm 2.1$ & & $9.1 \pm 2.1$ & & $8.3 \pm 2.2$ & & $2.9 \pm 3.1$ & \\
\hline Duration of IBD & & $<0.001$ & & 0.04 & & 0.89 & & $<0.001$ & & 0.45 & & 0.05 \\
\hline$>10$ years & $7.3 \pm 1.7$ & & $7.7 \pm 2.3$ & & $8.1 \pm 2.1$ & & $8.9 \pm 2.1$ & & $8.2 \pm 2.2$ & & $2.8 \pm 3.0$ & \\
\hline$\leq 10$ years & $7.2 \pm 1.8$ & & $7.5 \pm 2.5$ & & $8.1 \pm 2.0$ & & $9.2 \pm 2.3$ & & $8.5 \pm 2.2$ & & $3.0 \pm 3.1$ & \\
\hline Age at diagnosis & & $<0.001$ & & 0.98 & & 0.46 & & 0.52 & & 0.05 & & 0.42 \\
\hline A1: <16 years & $7.9 \pm 1.6$ & & $7.6 \pm 2.5$ & & $8.0 \pm 1.9$ & & $9.2 \pm 1.9$ & & $8.3 \pm 2.1$ & & $2.7 \pm 3.0$ & \\
\hline A2: $16-40$ years & $7.6 \pm 1.8$ & & $7.6 \pm 2.4$ & & $8.0 \pm 2.1$ & & $9.1 \pm 2.2$ & & $8.2 \pm 2.2$ & & $2.9 \pm 3.0$ & \\
\hline $\mathrm{A} 3:>40$ years & $7.2 \pm 1.9$ & & $7.6 \pm 2.6$ & & $8.2 \pm 2.1$ & & $9.2 \pm 2.2$ & & $8.6 \pm 2.1$ & & $3.0 \pm 3.3$ & \\
\hline Active worker or student & & 0.97 & & 0.02 & & 0.22 & & 0.02 & & 0.14 & & 0.54 \\
\hline Yes & $7.4 \pm 1.8$ & & $7.7 \pm 2.4$ & & $8.1 \pm 2.0$ & & $9.0 \pm 2.3$ & & $8.3 \pm 2.2$ & & $2.9 \pm 3.1$ & \\
\hline No & $7.4 \pm 2.0$ & & $7.4 \pm 2.7$ & & $8.0 \pm 2.3$ & & $9.3 \pm 2.0$ & & $8.4 \pm 2.2$ & & $3.0 \pm 3.3$ & \\
\hline BMI > $24 \mathrm{~kg} / \mathrm{m}^{2}$ & & 0.18 & & 0.03 & & 0.92 & & 0.91 & & 0.80 & & 0.91 \\
\hline Yes & $7.4 \pm 1.9$ & & $7.7 \pm 2.3$ & & $8.1 \pm 2.1$ & & $9.1 \pm 2.2$ & & $8.3 \pm 2.2$ & & $2.9 \pm 3.1$ & \\
\hline No & $7.5 \pm 1.8$ & & $7.5 \pm 2.6$ & & $8.1 \pm 2.0$ & & $9.1 \pm 2.2$ & & $8.3 \pm 2.2$ & & $3.0 \pm 3.3$ & \\
\hline Distance home - clinic & & 0.40 & & 0.30 & & 0.43 & & 0.14 & & 0.007 & & 0.002 \\
\hline$>25 \mathrm{~km}$ & $7.5 \pm 1.8$ & & $7.6 \pm 2.5$ & & $8.1 \pm 2.0$ & & $9.2 \pm 2.0$ & & $8.4 \pm 2.0$ & & $2.6 \pm 3.0$ & \\
\hline$\leq 25 \mathrm{~km}$ & $7.4 \pm 1.8$ & & $7.7 \pm 2.4$ & & $8.1 \pm 2.1$ & & $9.0 \pm 2.2$ & & $8.2 \pm 2.3$ & & $3.1 \pm 3.1$ & \\
\hline Current treatment & & 0.21 & & 0.002 & & 0.48 & & $<0.001$ & & 0.08 & & 0.02 \\
\hline None or 5 -ASA & $7.3 \pm 2.1$ & & $7.2 \pm 3.1$ & & $8.1 \pm 2.5$ & & $8.2 \pm 3.3$ & & $8.5 \pm 2.5$ & & $3.3 \pm 3.3$ & \\
\hline Immunosuppressant & $7.4 \pm 1.9$ & & $7.5 \pm 2.5$ & & $8.2 \pm 2.1$ & & $9.3 \pm 1.9$ & & $8.5 \pm 2.1$ & & $3.0 \pm 3.4$ & \\
\hline Biologics & $7.5 \pm 1.8$ & & $7.7 \pm 2.3$ & & $8.0 \pm 2.0$ & & $9.2 \pm 1.9$ & & $8.2 \pm 2.2$ & & $2.8 \pm 3.0$ & \\
\hline Current clinical remission & & $<0.001$ & & $<0.001$ & & $<0.001$ & & 0.78 & & $<0.001$ & & $<0.001$ \\
\hline Yes & $7.7 \pm 1.7$ & & $8.5 \pm 1.8$ & & $8.4 \pm 1.9$ & & $9.1 \pm 2.2$ & & $8.5 \pm 2.0$ & & $2.4 \pm 2.9$ & \\
\hline No & $7.3 \pm 1.9$ & & $6.5 \pm 2.7$ & & $7.7 \pm 2.2$ & & $9.1 \pm 2.1$ & & $8.1 \pm 2.3$ & & $3.4 \pm 3.1$ & \\
\hline
\end{tabular}

5-ASA: 5-aminosalicylates; BMI: body mass index; IBD: inflammatory bowel disease; VAS: visual analogic score.

Variables are presented as $\mathrm{n}(\%)$, mean \pm standard deviation

patients in clinical remission whereas the level of satisfaction with current treatment was higher in patients with long IBD duration ( $>10$ years), those with BMI $>24 \mathrm{~kg} / \mathrm{m}^{2}$, active workers or student, patients in clinical remission and patients treated with biologics and/or immunosuppressants ( Table 2 ). On the other hand, 93.9\% of patients felt the need for additional information about their current treatment. In addition to their treating physician, sources of information about their current treatment included the internet $(62.9 \%)$, general practitioners $(54.3 \%)$, newspapers and magazines $(18.2 \%)$, other patients $(14.4 \%)$, pharmacists $(11.5 \%)$ and educational programmes (6.7\%). The self-reported level of adherence to current treatment was high, with a mean score of $9.1 \pm 2.2$. The self-reported level of adherence to current treatment was higher in patients with ulcerative colitis, those with recent diagnosis $(\leq 10$ years), active workers or students and patients treated with biologics and/or immunosuppressants. Concerns about the current treatment were raised by $75.6 \%$ of patients and were related to the risk of adverse events (47.4\%), a lack of efficacy (32.9\%), the hospital's administration of biological agents (21.5\%), difficulties in the daily use of medicines $(5.9 \%)$ and difficulties with self-administered subcutaneous injection (4.9\%; this was reported by 9 out of 346 patients treated with subcutaneous injection of methotrexate, adalimumab, golimumab and/or methotrexate at the time of the survey) (Fig. 2).
Overall, $28.2 \%$ of patients reported that they used complementary and alternative medicines. The level of use of complementary and alternative medicines was $1.7 \pm 3.0$. (Fig. 1). The frequent use (VAS > 5) of complementary and alternative medicines was reported by $19.4 \%$ of patients.

Patients were asked whether they had heard of generic drugs and biosimilars, whether they had already taken some and if they were willing to take some if their GI specialist would give them a prescription. Whereas $86.7 \%$ and $77.6 \%$ of patients had already heard of or taken generics, respectively, only $20.4 \%$ and $11.0 \%$ had heard of or taken biosimilars. In patients treated with infliximab, $26.1 \%$ were aware of biosimilars, and $16.1 \%$ had received some. Regarding whether patients were willing to take a generic drug or a biosimilar, $53.5 \%$ and $21.5 \%$ responded positively, respectively, whereas $46.5 \%$ and $78.5 \%$ responded negatively or did not know the answer.

\subsection{Patients' experience with the patient-doctor relationship}

The mean number of physician appointments per year was $3.2 \pm 2.8$ for GI specialists and $2.6 \pm 3.9$ for general practitioners. Regarding patients' evaluation of the doctor-patient relationship with their IBD-treating physician, the mean VAS score was $8.3 \pm$ 2.2. The evaluation of the doctor-patient relationship was higher in 


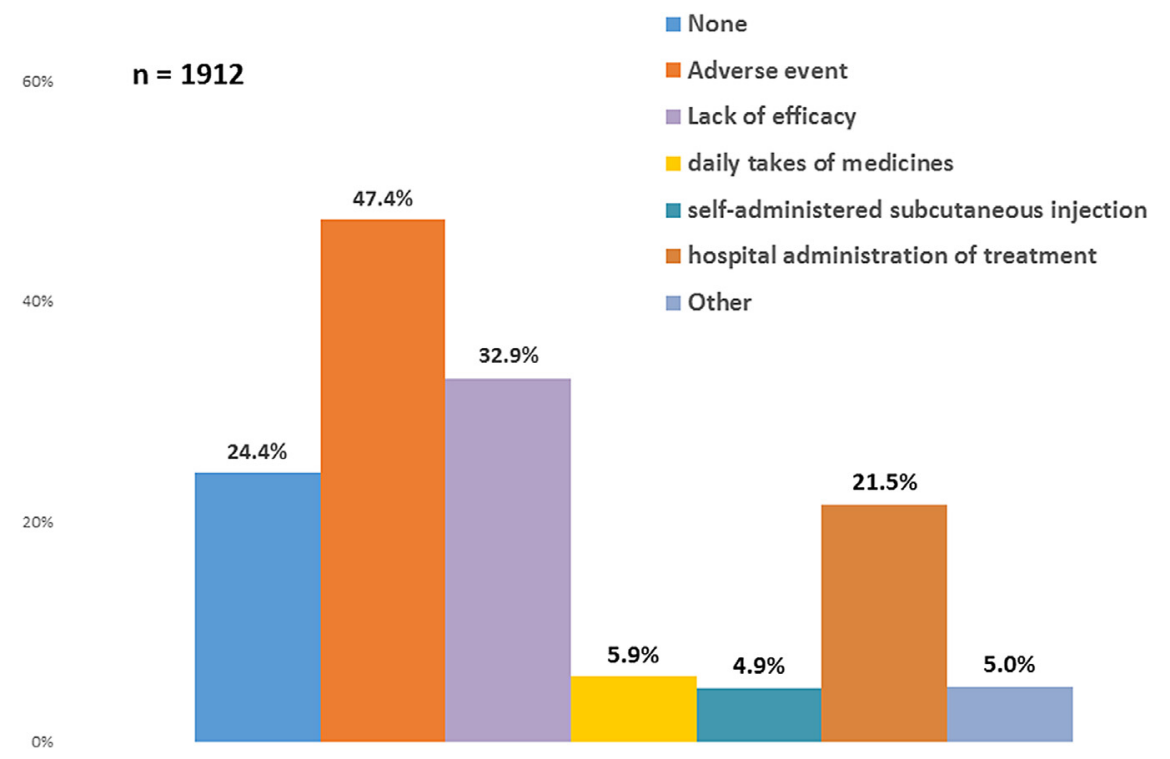

Fig. 2. Concerns about current treatment, measured using a multiple choice question.

patients $>40$ years, patients with ulcerative colitis, patients with diagnosis of IBD after 40 years (Montreal A3), patients in clinical remission and patients living far from the Clinic (> $25 \mathrm{~km})$ (Table 2). The mean VAS score regarding the need for additional information between appointments with their GI specialist was $2.9 \pm$ 3.1. In these cases, $62.6 \%, 31.6 \%$, and $1.5 \%$ of patients contacted their GI specialist by phone, email and mail, respectively. The need for additional informal between appointments with their GI specialist was increased with female gender, patients with ulcerative colitis, those with active disease, those not treated with biologics, those with recent diagnosis ( $\leq 10$ years) and those living close to the Clinic $(\leq 25 \mathrm{~km})$.

Beyond GI specialists, $62.0 \%$ of patients reported having previously consulted other healthcare professionals, including dieticians (47.3\%), psychotherapists (24.8\%), IBD nurses (16.6\%), social workers (9.3\%), sports coaches (4.9\%), and sexologists (1.9\%). A total of $89.2 \%$ of patients reported a perceived need for management with other healthcare professionals, including dieticians (24.9\%), sport coaches (22.0\%), psychotherapists (14.6\%), sexologists (9.4\%), social workers (8.4\%) and IBD nurses (6.4\%).

\section{Discussion}

This observational survey was primarily designed to assess the real-world experience of patients with IBD in the biologics era. During a single week, 2011 consecutive outpatients from 42 GETAID centres responded to this survey to assess the multidimensionality of patients' experiences with IBD. Despite inclusion of a very high rate of patients on biologics, we observed a high level of satisfaction, adherence to treatment and knowledge about IBD and IBD-related treatment. However, we highlighted a lack of knowledge and a lack of willingness to use generic drugs, biosimilars and educational programmes as well as perceived needs for combining IBD professionals with other healthcare professionals. Last, we highlighted the pivotal role of general practitioners in the management of IBD patients, which has not been sufficiently considered to date.

For a better understanding of our results, we aimed to introduce the French health care system, which is one of universal national health insurance. The financial and operational management of health insurance relies on compulsory income-proportional contributions, access to care according with needs (partial coverage for most of health care costs and full coverage in case of costly or long-term ailments) and determination of the prices of goods and services refunded. There are public hospitals as well as private hospitals that could be linked to the public system for nonprofit organization.

The overall acceptance of medication is often considered as a risk-benefit ratio [8]. In that setting, distinctions should be made between patients' perceived risk of treatment and evidence-based medicine. In addition, even if the benefits are superior to the risks, high concerns could remain and may affect long-term acceptance and adherence. In a recent study assessing beliefs about medicines in patients with longstanding infliximab therapy (median duration of 4.1 [2.3-6.0] years), concerns about medications were reported in approximately half of the patients [9]. In the present study, concerns about current treatment were raised in $75 \%$ of patients. The vast majority of concerns were related to the risk of adverse events and the risk of a lack of efficacy; there were fewer concerns about the mode of administration of treatments. Improving the quality of information and the implementation of shared decision-making processes is therefore mandatory in patients with IBD even in patients with longstanding disease and continuous treatment $[10,11]$.

Overweight is a common issue in adult patients with IBD like [12]. The increase of visceral adiposity may contribute to enhance the systemic inflammatory burden and impair the clinical course of IBD. In the present study, patients with BMI $\geq 24 \mathrm{~kg} / \mathrm{m}^{2}$ had paradoxically higher level of satisfaction with current treatment. We could hypothesize that patients with deeper remission and higher satisfaction with treatment may be more prone to express overweight predisposition.

Biosimilars were first introduced in the early 2010s based on the demonstration of pharmacokinetics and clinical biosimilarity with an originator $[13,14]$. They are now widely used in many inflammatory immune-mediated diseases, and they have a positive economic impact due to being more accessible for patients $[15,16]$. In two successive online surveys by the European Federation of Crohn's and Ulcerative Colitis Association in 2014-15 and 2018, $36 \%$ and $44 \%$ of the patients had previously heard of biosimilars, respectively $[17,18]$. Among them, only $32 \%$ and $35 \%$ were fully confident about the use of biosimilars even if they were prescribed by their treating physician. In our study, only $20.4 \%$ of patients had heard of biosimilars and only $21.5 \%$ were willing to take some. These results indicated a lack of knowledge and awareness about 
biosimilars. Efforts should be made to better inform patients about this topic through education programmes and to include these programmes in treatment-related decision-making processes.

Although direct access to information about IBD without guidance could generate anxiety, increasing knowledge about IBD and related treatments is a cornerstone in the management of patients with IBD $[10,19]$. Beyond GI specialists, patient education could be delivered through various supports such as the internet, newspapers and magazines, educational programmes, other patients associations and general practitioners. As previously described, most of our patients obtained information from the internet [19-21]. Surprisingly, despite our tertiary care centre recruitment, very few patients obtained additional information about IBD and related treatments from other patients and education programmes. Efforts to promote education programmes and daily interaction with other patients should be made to improve patients' access to education programmes.

Interestingly, more than half of the reported declared receiving additional information about IBD and their current treatment from their general practitioners. General practitioners are expected to play a pivotal role in the management of patients with chronic diseases based on a particular relationship developed over time, and thus, they can be an alternative source of information and management. To date, the role of general practitioners in the management of patients with IBD has been poorly studied and is often not considered in guidelines such as ECCO consensus statements $[5,6]$. Additional efforts should be made to reinforce the link between general practitioners and GI specialists and to set up education programmes on IBD for general practitioners.

Complementary and alternative medicine (CAM) encompasses a wide range of diverse medical and health care systems, practices and products that are not presently considered part of conventional medicine [22]. Although there is limited evidence on the efficacy of CAM in IBD, it is common to use CAM in patients with IBD [23,24]. The association Francois Aupetit, the French representative of the European Federation of the Crohn's and Ulcerative Colitis Association, recently administered an online survey on the use of CAM. Among the 767 participants, $65.6 \%$ reported a current use of CAM while an additional $12 \%$ reported a previous use of CAM [25]. In our study, only $28.2 \%$ of patients reported ever using CAM while $19.4 \%$ reported frequent use. In multivariate analysis (data not shown), the use of CAM was higher in women due to concerns about adverse events, concerns about a lack of efficacy of traditional treatment, the perceived need for a sexologist and a regulating defecation subscore $>5$. Our results may underline the heterogeneity between patients recruited in tertiary care centres or in patients associations.

The main purpose of the current study was to obtain a global perspective on the management of patients with IBD from the patient's point of view. Although the questionnaire provided a global overview of patients' management, knowledge and perceived needs, it may be biased by the absence of predefined outcomes and the multiplicity of the area of investigation. However, it provides useful information for improving daily practice with our patients and for developing a working hypothesis for further studies. One other limitation of this survey was the potential for recruitment bias. Indeed, two-thirds of the patients had Crohn's disease, most patients were treated with biologics, and approximately half of the patients had a history of intestinal resection, all of which are hallmarks of patients treated in tertiary care centres. However, patients with more severe IBD are probably the best target for more ambitious management, taking into account both new treatment and monitoring strategies and disability. Last, our questionnaire was developed with IBD-treating physicians and not by patients themselves, which may have led to the underestimation of some patient-reported outcomes.
In conclusion, this survey examined the provision of adequate and multidisciplinary care to patients with IBD and identified some gaps, especially with respect to patients' information on IBD and IBD-related treatment. Concerns about adverse events and a lack of efficacy should be more widely discussed in daily practice through shared decision-making processes. The role of the general practitioner is pivotal for patients and should be more adequately considered and reinforced in IBD units and in national and international organizations.

\section{Conflict of Interest}

Maria Nachury has received consulting and travel accomodation fees from Abbvie, Adacyte, Amgen, Biogen, Boehringer-Ingelheim, Ferring, Janssen, Mayoli Spindler, MSD, Takeda.

Yoram Bouhnik has received lecture and consulting fees from Abbvie, Biogaran, Boehringer-Ingelheim, CTMA, Ferring, Gilead, Hospira, ICON, Inception IBD, Janssen, Lilly, Mayoli Spindler, Merck, MSD, Norgine, Pfizer, Robarts Clinical Trials, Roche, Sanofi, Shire, Takeda, UCB and Vifor Pharma. This author has also stock ownership of Inception IBD, San Diego, CA, USA.

Melanie Serrero has received lecture or consulting fees from Abbvie, Ferring, Amgen, Celltrion, Janssen, Ferring, Takeda and Tillotts.

Jerome Filippi has received lecture and consulting fees from Abbvie, Astellas pharma, Covidien, Ferring, Jansen, MSD, Pfizer, Takeda.

Xavier Roblin reported a relationship with MSD, Abbvie, Amgen, Sandoz, Pfizer, Takeda and Janssen.

Guillaume Bouguen received lecture fees from Abbvie, Ferring, MSD, Takeda and Pfizer and consultant fees from Takeda, Janssen.

Denis Franchimont is research director of FNRS; he has received educational grants from Abbvie, Takeda, MSD, and has received honoraria fees for lectures or consultancy from Ferring, Falk, Chiesi, Abbvie, MSD, Centocor, Pfizer, Amgen, Janssen, Mundipharma, Takeda and Hospira.

Guillaume Savoye has received lecture fees from Vifor Pharma, Takeda, Pfizer, HAC Pharma, Abbvie, MSD, and Ferring France. This author has also received travel accommodations from Ferring, Abbvie, and MSD France as well as a research grant from Ferring.

Anthony Buisson has received research funding from Pfizer, lecture fees from Abbvie, Ferring, Hospira, MSD, Janssen, SanofiAventis, Takeda and Vifor Pharma and consulting fees from Abbvie, Biogen, Janssen, Pfizer and Takeda.

Edouard Louis has received fees for: Research Grant: Takeda, Pfizer; Educational Grant: Abbvie, Takeda, Janssen; Speaker Fees: Abbvie, Ferring, MSD, Falk, Takeda, Hospira, Janssen, Pfizer, Celgene; Advisory Board: Abbvie, Ferring, MSD, Takeda, Celgene, Hospira, Janssen; Consultant: Abbvie

Stephane Nancey has received consulting fees from Merck, Abbvie, Takeda, Ferring, Norgine, Vifor Pharma, Novartis, Janssen Cilag, Hospira, Takeda and HAC Pharma

Vered Abitbol has received lecture fees from Amgen, Biogen, Mylan, Sandoz, Pfizer, Takeda, Janssen, Tillots, Gilead, Ferring

Jean-Marie Reimund has received consulting fees from Hospira and Pfizer. This author has also received lectures fees from Abbvie, Ferring, Janssen Cilag, Pfizer and Takeda. This author has also received travel accommodations from Ferring, Abbvie, MSD, Janssen Cilag, Pfizer, Hospira and Takeda

Olivier DeWitt has received lecture and/or consultant fees from Abbvie, Ferring, Fresenius-Kabi, Janssen, Mylan, MSD, Pfizer, Takeda.

Lucine Vuitton has received lecture fees from Abbvie, MSD, Takeda, Ferring, Janssen and Pfizer, and research grants from MSD, Takeda and Pfizer. 
Nicolas Mathieu has received lecture fees from Abbvie, Amgen, Biogen, Janssen, MSD, Takeda, Pfizer, Ferring France and Vifor Pharma. This author has also received travel accommodations from Abbvie, Takeda and Pfizer as well as consulting fees from Amgen, Janssen, MSD, Sandoz,and Takeda.

Laurent Peyrin-Biroulet has received consulting fees from Merck, Abbvie, Janssen, Genentech, Ferring, Norgine, Tillots, Vifor, Shire, Therakos, Pharmacosmos, Pilège, BMS, UCB-Pharma, Hospira, Celltrion, Takeda, Biogaran, Boerhinger-Ingelheim, Lilly, Pfizer, and HAC-Pharma. This author has also received lecture fees from Merck, Abbvie, Takeda, Janssen Cilag, Ferring, Norgine, Tillots, Vifor, Therakos, HAC-Pharma, and Mitsubishi.

Cyrielle Gilletta received lecture fees from Abbvie, Takeda, Pfizer and Janssen and consulting fees from Abbvie, Janssen and Celltrion.

Matthieu Allez has received honoraria from Novo Nordisk, MSD, Abbvie, Ferring, Genentech, Janssen, Pfizer, GSK, Hospira, UCB, Novartis, Takeda, Mayolo-Spindler.

Stephanie Viennot has received consulting fees from Abbvie, MSD, Takeda, Vifor Pharma and Ferring.

Caroline Trang-Poisson has received lecture fees from MSD, Takeda, Janssen, Abbvie, Vifor Pharma and Norgine.

Medina Boualit has received travel accommodation from Abbvie, Janssen Takeda and Pfizer.

Lucile Boivineau has received consulting fees from Abbvie and Tillotts.

Mathurin Fumery has received lecture and consulting fees from Abbvie, MSD, Boehringer, Pfizer, Takeda, Janssen and Ferring.

Ludovic Caillo received board and lecture fees from Abbvie, Janssen, Pfizer, Takeda, Amgen

David Laharie has received counseling, boards, transports and/or fees from Abbvie, Biogaran, Biogen, Ferring, HAC-pharma, Janssen, MSD, Novartis, Pfizer, Prometheus, Roche, Takeda, Theradiag, Tillots.

Aurelien Amiot has received consulting fees from Abbvie, Hospira, Takeda, Gilead and Biocodex as well as lecture fees and travel accommodations from Abbvie, Janssen, Biocodex, Hospira, Ferring, Takeda and MSD. This author has also received advisory board fees from Gilead, Takeda and Abbvie.

No conflicts of interest are claimed by the remaining authors.

\section{Data availability statements}

The precise data underlying this article will be shared on reasonable request to the corresponding author.

\section{Study funding}

This study was supported by Abbvie with an institutional grant

\section{Supplementary materials}

Supplementary material associated with this article can be found, in the online version, at doi:10.1016/j.dld.2020.10.020.

\section{APPENDIX: Members of the GETAID-patients experience study group are as follows}

Aurelien Amiot, Sara Tadbiri, Charlotte Gagniere, Jenny Tannoury. Department of Gastroenterology, Henri Mondor Hospital, APHP, EC2M3-EA7375, Paris Est-Créteil Val de Marne University, Creteil, France.

Maria Nachury, Benjamin Pariente, Pauline Wils. Department of Gastroenterology, Huriez Hospital, Université of Lille, Lille, France.

Yoram Bouhnik, Carmen Stefanescu, Xavier Treton. Department of Gastroenterology, IBD and Nutrition Support, Beaujon Hospital, University Paris 7 Denis Diderot, Clichy, France
Melanie Serrero. Hôpital Nord, Centre d'investigation clinique Marseille Nord, Université Méditerranée, Marseille, France

Jerome Filippi, Xavier Hébuterne, Nadia Arab, Virginie Cluzeau. Department of Gastroenterology and Clinical Nutrition, CHU of Nice, University Côte d'Azur, Nice, France

Xavier Roblin, Emilie Del Tedesco. Department of Gastroenterology, Saint-Etienne University Hospital, Saint-Etienne, France.

Laurent Beaugerie, Philippe Seksik, Anne Bourrier, Cecilia Landmann, Julien Kirchgesner, Harry Sokol. Department of Gastroenterology, AP-HP, Hôpital Saint-Antoine, F-75012, ERL 1057 INSERM/UMRS 7203, UPMC Université Paris 6, Paris, France

Guillaume Bouguen, Laurent Siproudhis, Marie DeWitte. Department of Gastroenterology, CHU Rennes and University of Rennes, INCERM, CIC1414, NUMECAN institute,F-35000 Rennes, France

Denis Franchimont. Department of Gastroenterology, Hôpital Erasme, ULB, Brussels, Belgium

Guillaume Savoye. Department of Gastroenterology, Rouen University Hospital, Rouen, France.

Anthony Buisson. Department of Hepato-Gastroenterology, University Hospital Estaing of Clermont-Ferrand, Université d'Auvergne, Clermont-Ferrand, France

Edouard Louis, Catherine Reenaers. Department of Gastroenterology, Liège University Hospital, Liège, Belgium

Stephane Nancey, Gilles Boschetti, Claire Gay, Pauline Danion, Bernard Flourié. Department of Gastroenterology, Hospices Civils de Lyon and INSERM U1111, University Claude Bernard Lyon 1, Lyon, France.

Vered Abitbol, Georgia Malamut. Department of Gastroenterology, Cochin University Hospital, Paris, France

Jean-Marie Reimund, Benedicte Caron. Hôpitaux Universitaires de Strasbourg (Hôpital de Hautepierre) et INSERM U1113 IRFAC (Interface de Recherche Fondamentale et Appliquée en Cancérologie), Université de Strasbourg, Strasbourg, France

Olivier DeWitt. Cliniques Universitaires Saint-Luc, Brussels, Belgium

Lucine Vuitton. Department of Gastroenterology, Besancon University Hospital, Besancon, France

Nicolas Mathieu, Sandie Pestour. Department of HepatoGastroenterology and Digestive Oncology, Grenoble Alpes University Hospital, Grenoble, France.

Laurent Peyrin-Biroulet, Camille Zallot. INSERM U954 and Department of Gastroenterology, Université de Lorraine, Nancy, France

Cyrielle Gilletta. Department of Gastroenterology, Toulouse University Hospital, Toulouse, France.

Matthieu Allez, Jean-Marc Gornet, Clotilde Baudry. Department of Gastroenterology, Saint-Louis University Hospital, Paris, France.

Stephanie Viennot. Department of Gastroenterology, Caen University Hospital, Caen, France

Arnaud Bourreille, Caroline Trang-Poisson. Department of Gastroenterology, Nantes University Hospital, Nantes, France

Nina Dib. Department of HepatoGastroenterology, Angers University Hospital, Angers, France.

Hedi Brixi, Guillaume Cadiot. Department of GastroEnterology, Reims University Hospital, Rheims, France

Medina Boualit, Claire Painchart. Department of Gastroenterology, Valenciennes General Hospital, Valenciennes, France.

Laurianne Plastaras. Department of Hepato-Gastroenterology, Hospital Pasteur, Colmar, France.

Romain Altwegg, Lucile Boivineau. Department of Gastroenterology, Hôpital Saint-Eloi, University Hospital of Montpellier, Montpellier, France

Mathurin Fumery. Department of Gastroenterology, Amiens University Hospital, Amiens, France

Ludovic Caillo. Department of Gastroenterology, Nimes University Hospital, Nimes, France. 
David Laharie, Pauline Riviere, Florian Poullenot. Department of Hepato-Gastroenterology, University Hospital of Bordeaux, Hôpital Haut-Lévêque, Bordeaux, France

Benoit Coffin, Henri Duboc. Department of HepatoGastroenterology, Colombes University Hospital, Colombes, France.

Stephane Nahon. Department of Gastroenterology, Montfermeil

General Hospital, Montfermeil, France.

Noemie Tavernier. Department of Gastroenterology, Tourcoing Hospital, Tourcoing, France.

Marion Simon. Department of Gastroenterology, Institut Mutualiste Montsouris, Paris, France.

Baya Coulibaly. Department of HepatoGastroenterology, Avignon

Hospital, Avignon, France.

Morgane Amil. Department of HepatoGastroenterology, La

Roche sur Yon Hospital, La Roche sur Yon, France.

Duveau Nicolas. Department of HepatoGastroenterology,

Roubaix Hospital, Roubaix, France.

Sherine Khater. Department of Gastroenterology, Hôpital Européen Georges Pompidou, Paris, France

Mehdi Kaassis. Department of HepatoGastroenterology, Cholet Hospital, Cholet, France.

Felix Goutorbe. Department of HepatoGastroenterology, Cote Basque Hospital, Bayonne, France.

Driffa Moussata, Laurence Picon. Department of HepatoGastroenterology, Tours University Hospital, Tours, France.

\section{References}

[1] Torres J, Mehandru S, Colombel J-F, Peyrin-Biroulet L. Crohn's disease. Lancet 2017:389:1741-55. doi:10.1016/S0140-6736(16)31711-1.

[2] Ungaro R, Mehandru S, Allen PB, Peyrin-Biroulet L, Colombel J-F. Ulcerative colitis. Lancet 2017;389:1756-70. doi:10.1016/S0140-6736(16)32126-2.

[3] Peyrin-Biroulet L, Sandborn W, Sands BE, Reinisch W, Bemelman W, Bryant RV, et al. Selecting therapeutic targets in inflammatory bowel disease (STRIDE): determining therapeutic goals for treat-to-target. Am J Gastroenterol 2015;110:1324-38. doi:10.1038/ajg.2015.233.

[4] Marín-Jiménez I, Casellas F, Cortés X, García-Sepulcre MF, Juliá B, Cea-Calvo L, et al. The experience of inflammatory bowel disease patients with healthcare: a survey with the IEXPAC instrument. Medicine (Baltimore) 2019;98:e15044. doi:10.1097/MD.0000000000015044.

[5] Gomollón F, Dignass A, Annese V, Tilg H, Van Assche G, Lindsay JO, et al. 3rd European evidence-based consensus on the diagnosis and management of Crohn's disease 2016: part 1: diagnosis and medical management. J Crohns Colitis 2017:11:3-25. doi:10.1093/ecco-jcc/jjw168.

[6] Magro F, Gionchetti P, Eliakim R, Ardizzone S, Armuzzi A, Barreiro-de Acosta M, et al. Third European evidence-based consensus on diagnosis and management of ulcerative colitis. Part 1: definitions, diagnosis, extra-intestinal manifestations, pregnancy, cancer surveillance, surgery, and ileo-anal pouch disorders. J Crohns Colitis 2017;11:649-70. doi:10.1093/ecco-jcc/jjx008.

[7] Rouillon C, Peyrin-Biroulet L, Bouhnik Y, Louis E, Beaugerie L. Etat des lieux sur les MICI en France: enquete national du GETAID. Hépato-Gastro Oncol Digest 2019;26:167-76.
[8] Koliani-Pace JL, Haron AM, Zisman-Ilani Y, Thompson KD, Siegel CA. Patients' perceive biologics to be riskier and more dreadful than other IBD medications. Inflamm Bowel Dis 2019. doi:10.1093/ibd/izz121.

[9] Petitdidier N, Tannoury J, de'Angelis N, Gagniere C, Hulin A, Rotkopf H, et al. Patients' perspectives after switching from infliximab to biosimilar CT-P13 in patients with inflammatory bowel disease: a 12-month prospective cohort study. Dig Liver Dis 2019;51:1652-60. doi:10.1016/j.dld.2019.08.020.

[10] Lofland JH, Johnson PT, Ingham MP, Rosemas SC, White JC, Ellis L. Shared decision-making for biologic treatment of autoimmune disease: influence on adherence, persistence, satisfaction, and health care costs. Patient Prefer Adher 2017;11:947-58. doi:10.2147/PPA.S133222.

[11] Stacey D, Légaré F, Lewis K, Barry MJ, Bennett CL, Eden KB, et al. Decision aids for people facing health treatment or screening decisions. Cochrane Database Syst Rev 2017:4:CD001431. doi:10.1002/14651858.CD001431.pub5.

[12] Singh S, Picardo S, Seow SH. Management of inflammatory bowel diseases in special population: obese, old, or obstetric. Clin Gastroenterol Hepatol 2020;18(6):1367-80 Clin Gastroenterol Hepatol 2020;18:1367-80.

[13] Komaki Y, Yamada A, Komaki F, Kudaravalli P, Micic D, Ido A, et al. Efficacy, safety and pharmacokinetics of biosimilars of anti-tumor necrosis factor- $\alpha$ agents in rheumatic diseases; A systematic review and meta-analysis. J Autoimmun 2017:79:4-16. doi:10.1016/j.jaut.2017.02.003.

[14] Edwards CJ, Hercogová J, Albrand H, Amiot A. Switching to biosimilars: current perspectives in immune-mediated inflammatory diseases. Expert Opin Biol Ther 2019:19:1001-14. doi:10.1080/14712598.2019.1610381.

[15] Baumgart DC, Misery L, Naeyaert S, Taylor PC. Biological therapies in immunemediated inflammatory diseases: can biosimilars reduce access inequities? Front Pharmacol 2019;10:279. doi:10.3389/fphar.2019.00279.

[16] Pentek M, Zrubka Z, Gulacsi L. The economic impact of biosimilars on chronic immune-mediated inflammatory diseases. Curr Pharm Des 2017;23:6770-8. doi:10.2174/1381612824666171129193708.

[17] Peyrin-Biroulet L, Lönnfors S, Roblin X, Danese S, Avedano L. Patient perspectives on biosimilars: a survey by the European federation of crohn's and ulcerative colitis associations. J Crohns Colitis 2017;11:128-33. doi:10.1093/ecco-jcc/ jjw138.

[18] Peyrin-Biroulet L, Lönnfors S, Avedano L, Danese S. Changes in inflammatory bowel disease patients' perspectives on biosimilars: a follow-up survey. United Eur Gastroenterol J 2019;7:1345-52. doi:10.1177/2050640619883704.

[19] Selinger CP, Carbery I, Warren V, Rehman AF, Williams CJ, Mumtaz S, et al. The relationship between different information sources and disease-related patient knowledge and anxiety in patients with inflammatory bowel disease. Aliment Pharmacol Ther 2017;45:63-74. doi:10.1111/apt.13831.

[20] Selinger CP, Lal S, Eaden J, Jones DB, Katelaris P, Chapman G, et al. Better disease specific patient knowledge is associated with greater anxiety in inflammatory bowel disease. J Crohns Colitis 2013;7:e214-18. doi:10.1016/j.crohns. 2012.09.014.

[21] Cima RR, Anderson KJ, Larson DW, Dozois EJ, Hassan I, Sandborn WJ, et al. Internet use by patients in an inflammatory bowel disease specialty clinic. Inflamm Bowel Dis 2007;13:1266-70. doi:10.1002/ibd.20198.

[22] Complementary, alternative, or integrative health: what's in a name? 2018.

[23] Hilsden RJ, Verhoef MJ, Rasmussen H, Porcino A, DeBruyn JCC. Use of complementary and alternative medicine by patients with inflammatory bowel disease. Inflamm Bowel Dis 2011;17:655-62. doi:10.1002/ibd.21360.

[24] Torres J, Ellul P, Langhorst J, Mikocka-Walus A, Barreiro-de Acosta M, Basnayake C, et al. European crohn's and colitis organisation topical review on complementary medicine and psychotherapy in inflammatory bowel disease. J Crohns Colitis 2019:13:673 -685e. doi:10.1093/ecco-jcc/jiz051.

[25] Abitbol V, Lahmek P, Buisson A, Olympie A, Poupardin C, Chaussade S, et al. Impact of complementary and alternative medicine on the quality of life in inflammatory bowel disease: results from a French national survey. Eur J Gastroenterol Hepatol 2014;26:288-94. doi:10.1097/MEG.0000000000000040. 